\title{
How do Positive Views Maintain Life Satisfaction?
}

\author{
Chia-Huei Wu $\cdot$ Ying-Mei Tsai $\cdot$ Lung Hung Chen
}

Accepted: 16 June 2008/Published online: 1 July 2008

(C) Springer Science+Business Media B.V. 2008

\begin{abstract}
This study proposes three mediation pathways to explain how the positive views (perceived control, optimism and self-enhancement) proposed by Cummins and Nistico (Journal of Happiness Studies 3:37-69 2002) maintain life satisfaction. The three pathways were enhancing self-esteem, reducing have-want discrepancy and changing importance perceptions. Two hundred and seventy-two undergraduates from Central Taiwan University of Science and Technology and Nan Kai Institute of Technology voluntarily participated in this study. Questionnaires measuring sense of control, optimism, self-enhancement, self-esteem, have-want discrepancy and importance of life domains, and global life satisfaction were administered to participants in a classroom setting. Correlation and structural equation modeling analyses were conducted to examine the mediation effects of these three pathways. Generally, results of correlation and structural equation modeling analyses were consistent with hypothesized relations among variables and showed that the relationship between positive views and life satisfaction was completely mediated by self-esteem, have-want discrepancy and shifting tendency of importance perception, indicating that the three pathways of enhancing self-esteem, reducing havewant discrepancy and changing importance perceptions had unique effects to explain how positive views maintain life satisfaction.
\end{abstract}

Keywords Control · Optimism · Self-enhancement · Self-esteem · Discrepancy · Life satisfaction

C.-H. $\mathrm{Wu}$

Institute of Business and Management, National Chiao Tung University, Hsinchu, Taiwan, Republic of China

Y.-M. Tsai

Office of Physical Education, Central Taiwan University of Science and Technology, Taichung, Taiwan, Republic of China

L. H. Chen $(\bowtie)$

Graduate Institute of Physical Education, National Taiwan Sport University, Taoyuan County, P.O. Box 59182, Taipei 100, Taiwan, Republic of China e-mail: fjudragon@yahoo.com.tw 


\section{Introduction}

Research has demonstrated that life satisfaction has a homeostatic property with stability at a moderately positive level (e.g., Chamberlain and Zika 1992; Cummins 1995, 1998; Koivumaa-Honkanen et al. 2005). In order to explain this homeostatic phenomenon, Cummins and Nistico (2002) proposed that positive cognitive bias from three positive views pertaining to the self plays an important role in maintaining life satisfaction. Specifically, people have a motivation to fulfill the need of self-esteem, and in order to gain success and avoid failure in domains of contingency, people regulate their goals and actions according to contingencies of self-worth (Crocker et al. 2006). Since self-esteem was the factor that was most strongly associated with life satisfaction, Cummins and Nistico (2002) argued that life satisfaction would also influenced by the same mechanism as self-esteem in the three positive beliefs of perceived control, optimism and selfenhancement. That is, it was expected that three positive beliefs also play important roles in maintaining a sense of positive well-being.

Although Cummins and Nistico (2002) identified three positive views (perceived control, optimism and self-enhancement) that may maintain an individual's life satisfaction, these authors did not empirically examine how the three positive views maintain life satisfaction. Hence, the purpose of this study is to propose possible pathways through which positive views maintain life satisfaction and then empirically test the hypothesized pathways. In other words, we would like to find possible mediators to explain the relationship between positive views and life satisfaction. According to Cummins and Nistico's (2002) basic ideas, it was proposed that fulfilling the need of self-esteem is an important pathway for the three positive views to maintain life satisfaction. This pathway can be directly traced to self-research in social psychology. First, the positive relationships between the three positive views (perceived control, optimism and selfenhancement) and self-esteem has been demonstrated in past studies (e.g., Brown et al. 1988; Judge et al. 2002; Kobayashi and Brown 2003; Makikangas et al. 2004; Scheier et al. 1994; Wood et al. 1994). Second, the strong relationship between self-esteem and life satisfaction is also commonly discussed in the literature (e.g., Cummins and Nistico 2002; Diener and Diener 1995). Therefore, it is reasonable to expect that one pathway for the three positive views to foster life satisfaction is through the effect of embracing self-esteem.

However, in addition to the self-esteem pathway, two pathways identified by Wu (in press a) that are directly related to a life satisfaction evaluation may permit the positive views to maintain life satisfaction. In the following paragraphs, we first introduce these two pathways for enhancing life satisfaction and then link them to the positive views to describe how the three positive views maintain life satisfaction through these two pathways.

The first pathway to promote life satisfaction identified by $\mathrm{Wu}$ (in press a) is reducing have-want discrepancy in life domains, because have-want discrepancy is regarded as the root of dissatisfaction (e.g., Campbell et al. 1976; Calman 1984; Diener et al. 1985; Locke 1969, 1976; Michalos 1985; Shin and Johnson 1978) and many empirical studies have shown that the range of have-want discrepancies determines the level of satisfaction (e.g., Cohen 2000; Schulz 1995; Vermunt et al. 1989; Welham et al. 2001; Wu and Yao 2006a). In a recent study, $\mathrm{Wu}$ (in press b) further reported that satisfaction measurement involve an implicit have-want comparison. In his study, relationships between direct have-want discrepancy, amount, and satisfaction, which vary in their degree of explicitness, were examined. The have-want discrepancy measure explicitly asks respondents to rate the 
discrepancy between what they have and what they want (e.g., What is the difference between your energy level and the level you would like to have?). The amount measure requires respondents to think about the amount of discrepancy between what one has and what one wants, but does not explicitly ask about that (e.g., Do you have enough energy for everyday life?). Finally, the satisfaction measure is assumed to incorporate a component of the have-want comparison, but does not ask respondents to consider such a comparison in the question (e.g., Are you satisfied with your energy?). Results of correlation analysis showed that satisfaction has a closer relation with amount than have-want discrepancy. In addition, results of conventional mediation analysis and multilevel path analysis both showed that have-want discrepancy influences amount, which then influences satisfaction, suggesting that transformation of have-want status comparison into satisfaction evaluation occurs via an intermediate stage (amount) during which the have-want status comparison is made indirectly. This is evidence for the discrepancy nature of satisfaction evaluation. As a result, it is a straightforward approach to enhance an individual's life satisfaction by reducing have-want discrepancy in life domains.

The other pathway identified by $\mathrm{Wu}$ (in press a) to enhance life satisfaction is to attune the importance perception of life domains according to the level of have-want discrepancy of each domain, which is termed "value perception" pathway. That is, we can enhance an individual's life satisfaction by shifting their importance perception in life areas. Several studies have found that people will change the importance of life domains or re-conceptualize the meaning of life according to their health status (e.g., Rapkin 2000; Rapkin and Shwartz 2004; Schwartz et al. 1997; Jansen et al. 2000); and people who can shift their importance perception of different life goals according to their situations have higher life satisfaction (e.g., Moskowitz et al. 1996; Rapkin 2000; Tunali and Power 1993; Wrosch and Heckhausen 1999; Wrosch et al. 2003). Moreover, in self-concept research, it has been found that people tend to stress their self-concept with better performance (e.g., Crocker et al. 2003; Hardy and Moriarty 2006) and people with a strong tendency to discount the importance of worse self-concepts have higher self-esteem (Pelham and Swann 1989). Regarding life satisfaction, Wu (in pressa) recently proposed an individual difference index to indicate each person's tendency of upgrading the importance of life domains with lower discrepancy and downgrading the importance of life domains with larger discrepancy (termed "shifting tendency"). And he found that this shifting tendency was positively correlated to life satisfaction; even when the effect of have-want discrepancy was controlled in a regression model. Therefore, reducing have-want discrepancy and changing importance perception are two approaches for maintaining and enhancing life satisfaction directly.

According to Cummins and Nistico's (2002) notions on the positive cognitive bias of the three positive views (perceived control, optimism and self-enhancement), it can be expected that people with a higher level of perceived control, optimism and selfenhancement would have lower have-want discrepancy in life domains due to their positive outlook of life. Cummins and Nistico (2002) stated that the cognitive bias derived from the three positive views is "belief based in reality but with a positive bias in favor of the individual (p. 52)". Hence, because people with higher levels of perceived control, optimism and self-enhancement tend to attribute success to them, hold positive belief in the future, and think they are better than average others, they would have more confidence to believe that their current life approaches the life that they want, and thus they report less have-want discrepancy in life.

Furthermore, Cummins and Nistico (2002) also proposed that the three positive views can maintain life satisfaction as a form of assumptive schema-a knowledge structure used 
for understanding, interpreting and predicting information. Specifically, the three positive views can make persons hold positive views for themselves and form a positive schema for themselves. Because people tend to use their schemata to process information, they tend to select information congruent with their schemata and neglect information incongruent with schemata. For example, self-verification theory contends that people need to seek confirmation of their self-concept because a stable self-view provides people with a crucial source of coherence (Swann et al. 2002). With this motivation, people create social environments that reinforce their self-view and develop perceptions that are compatible with their self-view (Swann et al. 2002). Several studies of self-verification theory have revealed that people with high self-certainty reinterpret self-inconsistent feedback to be more consistent (Swann and Read 1981) and actively resist others' attempts to change their self-view (Swann and Ely 1984; Swann et al. 1988). Hence, the schema formed by positive views may lead an individual to selectively focus on life events that show a match between current life status and the want status when he/she makes a have-want discrepancy judgment for a certain life domain and report less have-want discrepancy. In addition to reducing have-want discrepancy for specific domains, the selective attention guided by the positive schema would also occur across domains by leading an individual to stress life domains with lower have-want discrepancy and to neglect life domains with larger havewant discrepancy (the shifting tendency introduced above). Therefore, we expected that the three positive views proposed by Cummins and Nistico (2002) can maintain life satisfaction both by reducing have-want discrepancy and by strengthening shifting tendency.

In summary, we proposed that there are three pathways through which the three positive views can maintain life satisfaction. The first one is enhancing self-esteem, the second one is reducing have-want discrepancy of life domains and the third one is shifting importance perception among life domains. A structural equation model is conducted to determine if the effects of these pathways are significant and unique. The proposed model is displayed in Fig. 1. The three positive views will be used to indicate a latent factor in modeling because they are germane to the positive view toward self.

In addition to the model proposed in Fig. 1, an alternative model (see Fig. 2) was also built. The difference between the original model and the alternative model lies in the model specification of positive views and the self-related mediator. This alternative model was derived from the homeostatic model (Cummins et al. 2002), in which self-esteem, sense of control and optimism were regarded as three cognitive buffers to maintain life satisfaction. Accordingly, it would be inferred that self-esteem should be clustered with sense of control and optimism as a component of positive views, and the self-enhancement then should be placed as the mediator between positive views and life satisfaction. The

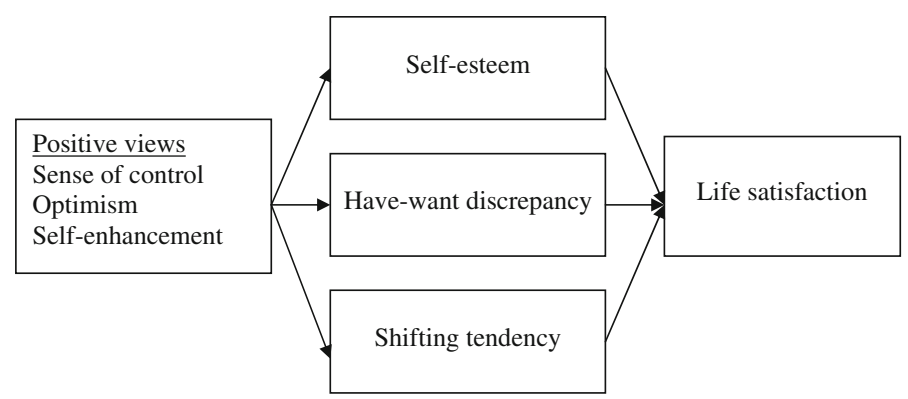

Fig. 1 The hypothesized research model 


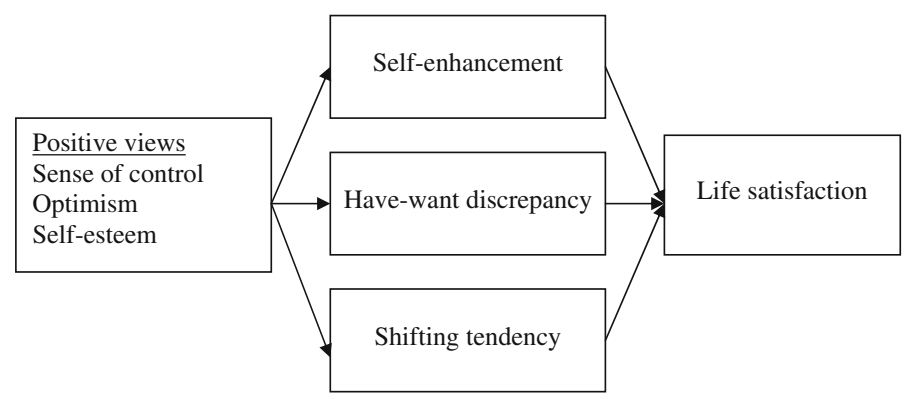

Fig. 2 The alternative model

rationale behind this model was that positive views will trigger a self-enhancement motivation and then lead a higher life satisfaction. This rationale was different from that of the original model in Fig. 1, which regards self-enhancement, sense of control and optimism as the three components of positive views and as the means to purse and fulfill the need of self-esteem. Although the model in Fig. 1 was close to the original propositions in Cummins and Nistico's (2002) article, including the alternative model derived from the homeostatic model in Fig. 2 can also facilitate us to figure out the operation of self-related mechanism in maintaining life satisfaction.

\section{Method}

\subsection{Participants and Procedure}

Two hundred and seventy-two (118 male and 154 female) undergraduates from Central Taiwan University of Science and Technology and Nan Kai Institute of Technology voluntarily participated in this study. Their age ranged from 18 to 23 years old $(M=19.70$, $S D=1.36$ ). A set of self-report questionnaires was administered to the participants in a classroom setting. Participants' confidentiality and anonymity were assured. After completing the questionnaires, participants returned them to the administrator directly.

\subsection{Instruments}

\subsubsection{Sense of Control Scale}

It should be noted that in Cummins and Nistico's (2002) article, the sense of control was referred to primary control (Rothbaum et al. 1982), which involves a mastery and active tendency in changing environment, rather than the secondary control, which involves a fitfocused tendency to adjust oneself to the current environment. Hence, a scale for assessing primary control was used in the current study.

The personal control subscale from the Spheres of Control Scale-revised version (SOC-R; Paulhus and Van Selst 1990) was used. Paulhus and Van Selst (1990) differentiates the concept of locus of control into three major spheres of life: personal control, interpersonal control, and social-political control. There are 10 items in each subscale. Participants respond with a seven-point Likert scale, anchoring from 1 (strongly disagree) to 7 (strongly agree). In this study, only the personal control subscale was administered. However, previous studies showed that only items with positive wording showed higher loadings (above 0.40) 
on the same factor (Spittal et al. 2001) or that items with positive wording and negative wording are loaded on two factors associated with the wording style (Wu and Yao 2007). These findings suggested that positively and negatively worded items might have different meanings, since the two factors underlying the scale were not strongly correlated (factor correlation was -.20). Similar results were also obtained for the current sample (factor correlation was -.13). Since items with positive wording are typical control statements across measurements on the sense of control (see Lefcourt 1991), only the positively worded items were used to index the sense of control. Specifically, they are: (Item 1) I can usually achieve what I want if I work hard for it; (Item 2) Once I make plans, I am almost certain to make them work, (Item 4) I can learn almost anything if I set my mind to it, (Item 5) My major accomplishments are entirely due to my hard work and ability, and (Item 8) Almost anything is possible for me if I really want it. The mean of these five items represented the level of sense of control. The Cronbach's alpha of the five items was 0.77 .

\subsubsection{The Life Orientation Test-Revised}

The Life Orientation Test-Revised (LOT-R, Scheier et al. 1994) was used to assess individual differences in generalized optimism ( 3 items) versus pessimism ( 3 items). For the Chinese population, Lai et al. (1998) reported that the LOT-R is a reliable and valid measure of dispositional optimism among Hong Kong Chinese and a confirmatory factor analysis showed that the LOT-R represents a one-factor model of optimism. In Lai and Yue's (2000) study, their results also indicated that the LOT-R exhibited convergent and discriminant validity in Hong Kong and Mainland Chinese. However, confirmatory factor analysis with the Mainland sample showed that the positively and the negatively worded items split into two factors. In order to ensure the dimensionality of this scale for the current sample, exploratory factor analysis was conducted, and results supported a two factor model, indicating that the scale has two wording factors: one factor consists of positively worded items (optimism factor), and the other one consists of negatively worded items (pessimism factor). The factor correlation was -.23 , suggesting that items for optimism and pessimism might not have the same meaning in one dimension. Thus, in this study, only optimism items were used to calculate the optimism score. The Cronbach's alpha was 0.69.

\subsubsection{Self-Enhancement Scale}

Self-enhancement was measured by Kurman's (2001) instrument. Participants were asked to rate themselves in six traits (intelligence, sociability, health, honesty, cooperation, and generosity) and to rate common people for the same traits as well. Level of selfenhancement was then computed by subtracting rating scores for common people from rating scores for self. In other words, level of self-enhancement was indicated by the gap between ratings for self and common people. Mean gap scores across six traits were computed for each participant. A larger score represented a stronger self-enhancement tendency. The Cronbach's alpha of the scale was .62 .

\subsubsection{Self-Esteem Scale}

The Rosenberg's (1965) 10-item self-esteem scale was used to measure participants' generalized, global feelings of self-worth. Participants respond to statements on positive 
and negative feelings about the self, such as "I am able to do things as well as most other people" on a Likert 7-point scale ranging from 1 (strongly disagree) to 7 (strongly agree). The self-esteem scale has shown good reliability and validity. On reliability, the internal reliability ranged from .77 to .88; the test-retest reliability coefficient ranged from .82 (2-week interval) to .85 (1-week interval). Regarding validity, the self-esteem scale demonstrated adequate construct validity, convergent validity, and discriminant validity (see Robinson et al. 1991). The internal reliability in the current sample was 0.83 .

\subsubsection{Quality of Campus Life Questionnaire}

This questionnaire contains 15 items selected by Wu and Yao (2006b) in accordance with student life to measure college students' have-want discrepancy and importance perception in different domains on a Likert-typed scale ranging from -4 (large discrepancy from the want status) to 0 (the same with want status) (they were transformed to $1-5$ in analysis) and 1 (not at all important) to 5 (very important), respectively. The 15 items were: living environment, campus environment, learning atmosphere, social and political environment, transport, money, eating, health, sleep, leisure activities, energy, non-study performance, learning performance, social relationships, and social support. In this study, the Cronbach's alpha of the have-want discrepancy ratings and importance ratings were .85 and .85 , respectively. From this scale, mean have-want discrepancy score was calculated to indicate an individual's domain quality of life. It should be noted that a large score indicates a small have-want discrepancy. In addition, shifting tendency was also computed as by Wu (in press a), by correlating discrepancy scores with importance scores across all items for each individual. Pearson correlation coefficients were then transformed into Fisher's Z values. Higher values indicated a stronger tendency of stressing life domains with lower discrepancy and discounting life domains with larger discrepancy.

\subsubsection{Satisfaction with Life Scale}

The Satisfaction with Life Scale (SWLS), developed by Diener et al. (1985), is a widelyused measure of subjective well being. Diener et al. (1985) defined life satisfaction as conscious cognitive judgment of life in which individuals compare their life circumstances with a self-imposed standard. The scale contained 5 items and employed a 7-point Likert scale, with higher values corresponding to a higher degree of satisfaction. The mean score was calculated to represent the level of satisfaction. The SWLS has shown good reliability and validity (see Pavot and Diener 1993). In the Taiwan-published Chinese-translated version, the $\mathrm{Wu}$ and Yao (2006c) study confirmed the single-factor structure of the SWLSTaiwan version, and revealed that the SWLS-Taiwan version was factor invariant across gender. In this study, the Cronbach's alpha of the scale was .87.

\section{Results}

Table 1 presents descriptive statistics of research variables, including mean, standard deviation, and correlations. First, it can be seen that the three regulators (sense of control, optimism and self-enhancement) were positively correlated $(r=.20$ to $.52, p s<.001)$. Second, these three regulators were all positively correlated with self-esteem ( $r=.23$ to .52 , $p s<.001)$ and shifting tendency $(r=.12$ to $.15, p s<.001)$, but only sense of control and 
Table 1 Descriptive statistics of research variables

\begin{tabular}{|c|c|c|c|c|c|c|c|c|}
\hline \multirow[t]{2}{*}{ Variables } & \multirow[t]{2}{*}{ Mean } & \multirow[t]{2}{*}{$S D$} & \multicolumn{6}{|c|}{ Correlation } \\
\hline & & & 1 & 2 & 3 & 4 & 5 & 6 \\
\hline 1. Sense of control & 4.93 & 0.85 & - & & & & & \\
\hline 2. Optimism & 4.64 & 1.06 & $.52 * * *$ & - & & & & \\
\hline 3. Self-enhancement & -0.96 & 9.08 & $.24 * * *$ & $.20 * * *$ & - & & & \\
\hline 4. Self-esteem & 4.64 & 0.84 & $.41 * * *$ & $.52 * * *$ & $.23 * * *$ & - & & \\
\hline 5. Discrepancy & 3.06 & 0.63 & $.16^{* *}$ & $.28 * * *$ & .04 & $.25 * * *$ & - & \\
\hline 6. Shifting tendency & -0.03 & 0.34 & $.12^{*}$ & $.14^{*}$ & $.15^{*}$ & $.15^{*}$ & .07 & - \\
\hline 7. Life satisfaction & 4.22 & 1.10 & $.26 * * *$ & $.36 * * *$ & .04 & $.43 * * *$ & $.34 * * *$ & $.27 * * *$ \\
\hline
\end{tabular}

$* p<0.05, * * p<0.01, * * * p<0.001$

optimism were positively correlated with have-want discrepancy $(r=.16$ and $.28, p s<.01)$ and life satisfaction $(r=.16$ and $.28, p s<.001)$. Third, among the three mediators, self-esteem had positive relationships to have-want discrepancy and shifting tendency ( $r=.25$ and .15 , $p s<.05$ ), and have-want discrepancy and shifting tendency were uncorrelated. Finally, selfesteem, have-want discrepancy and shifting tendency were all positively correlated with life satisfaction $(r=.27$ to .43 , ps $<.001)$.

Structural equation modeling was then used to examine the proposed model in Fig. 1. The exact specified model is shown in Fig. 3, in which the three regulators were influenced by a factor called positive views (factor variance was set as 1), which had direct effects on the three mediators, self-esteem, have-want discrepancy and shifting tendency. Finally, the three mediators all had direct effects on life satisfaction. This model was estimated by a maximum likelihood estimator with robust correction using Mplus (Muthén and Muthén 2007) because the self-enhancement variable slightly departed from a normal distribution.

The Satorra-Bentler chi-square value of this model was $15.67(\mathrm{df}=12, p>.05$ ), retaining the model. In addition, the values of the four fit indices suggested by $\mathrm{Hu}$ and Bentler (1999) in this model were all acceptable (TLI $=.98$; CFI $=.99$; RMSEA $=.034$; SRMR $=.032$ ). In this model, all parameters were significant at $p<0.01$. Standardized estimates are also displayed in Fig. 3.

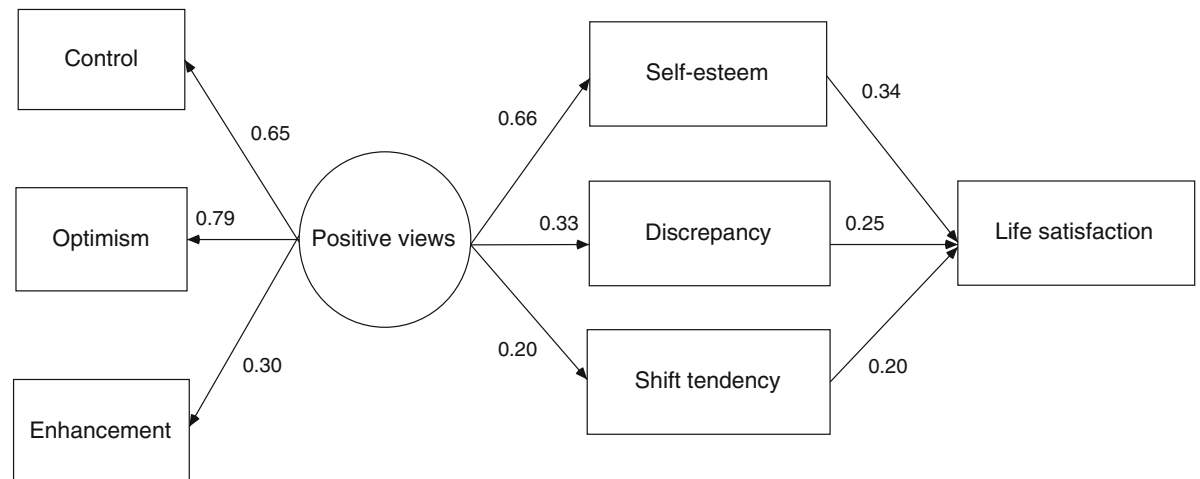

Fig. 3 Standardized estimates in the model. All estimates were significant at $p<0.01$. Error terms were omitted for simplicity 
Moreover, three indirect effects (mediation effects) from positive views to life satisfaction through the three mediators were tested. The unstandardized/standardized mediation effect of self-esteem, have-want discrepancy and shifting tendency were $.25 / .23$ $(p<.01), .09 / .08(p<.01)$ and $.04 / .04(p<.05)$, respectively, and all of these were significant, revealing that each mediator has a unique effect.

In order to ensure that these three mediators can completely mediate the effect of positive views on life satisfaction, the direct effect of positive views on life satisfaction was added in the model and re-estimated parameters. Results showed that the direct effect of positive views on life satisfaction was not significant. Hence, all these results demonstrated that self-esteem, have-want discrepancy and shifting tendency completely mediated the positive relationship between positive views and life satisfaction. Furthermore, additional analyses also found that paths among the three mediators (self-esteem, have-want discrepancy and shifting tendency) were all non-significant, revealing that the three pathways were independent.

Finally, the alternative model in Fig. 2 was examined using the same procedure. The Satorra-Bentler chi-square value of this model was 49.14 ( $\mathrm{df}=12, p<.05$ ), rejecting this model. In addition, the values of the four fit indices were unacceptable (TLI $=.76$; $\mathrm{CFI}=.86$; RMSEA $=.11$; SRMR $=.08$ ). Given its poor fit, we did not report specific estimates here. Fit indices for model comparison (AIC \& BIC; lower value is better) revealed that the original model $(\mathrm{AIC}=5392.343$; $\mathrm{BIC}=5475.277)$ was better than the alternative model $(\mathrm{AIC}=5430.125 ; \mathrm{BIC}=5513.058)$.

\section{Discussion}

This study proposed three mediation pathways to explain how the positive views proposed by Cummins and Nistico (2002) maintain life satisfaction. The three pathways are: enhancing self-esteem, reducing have-want discrepancy and changing importance perceptions. Correlation and structural equation modeling analyses were conducted to examine the mediation effects of these three pathways. Generally, results of correlation and structural equation modeling analyses were consistent with hypothesized relationships among the variables and showed that each pathway has a unique mediation effect on the relationship between positive views and life satisfaction. Among these three pathways, results of indirect effects (mediation effect) further indicated that enhancing self-esteem has the largest mediation effect, and that changing importance perception has the smallest mediation effect; reducing have-want discrepancy is in the middle. This finding reveals that self-esteem indeed plays a substantial role in maintaining life satisfaction. This conclusion was also supported by comparing the alternative model derived from the homeostatic model (Cummins et al. 2002). The alternative model which changed the positions of self-esteem and self-enhancement had poor fit and was worse than the hypothesized model. This finding revealed that regarding the self mechanism, the effect of positive views on life satisfaction is through the fulfillment of self-esteem, rather than through a self-enhancement motivation.

However, several non-significant findings in the correlation analysis are worth discussing here because they are related to theoretical and measurement concerns. The three non-significant correlations are: (1) the correlation between self-enhancement and havewant discrepancy, (2) the correlation between self-enhancement and life-satisfaction and (3) the correlation between have-want discrepancy and shifting tendency. First, it seems that the non-significant correlations between self-enhancement and have-want discrepancy 
and life satisfaction were not consistent with expectations, given that Cummins and Nistico (2002) argued that self-enhancement is one component of positive views for maintaining life satisfaction. Although Cummins and Nistico (2002) did not explicitly indicate that the three positive views should have direct effects on life satisfaction, it still be expected that the three positive views would have a positive relationship with life satisfaction and its antecedents, have-want discrepancy.

A possible explanation of the non-significant correlation between self-enhancement and life satisfaction is related to the measurement of self-enhancement. In this study, selfenhancement was indicated by the gap between ratings for self and other common people on six positive personality traits (intelligence, sociability, health, honesty, cooperation, and generosity). Although this measurement method is consistent with the concept of selfenhancement, the traits used here may not relate to life evaluation, especially to the havewant discrepancy judgments for life domains. If the evaluated traits were changed to happy, extroverted and other happiness-related traits, then a positive effect of selfenhancement on have-want discrepancy and life satisfaction would be observed. In other words, the positive effect of self-enhancement on have-want discrepancy and life satisfaction may rely on the domain-specific meaning of self-enhancement. In contrast, the positive relationship between self-enhancement and shifting tendency does not have to rely on the domain-specific meanings of self-enhancement, because shifting tendency is an attention-wise construct, which can be directly guided by the tendency of holding positive self views based on self-enhancement motivation, no matter which content is used for assessing self-enhancement. This is why the self-enhancement measure based on the six traits used here still has a positive relationship with shifting tendency. This notion could be used to explain the non-significant results associated with self-enhancement, but further examination is needed. Nevertheless, the non-significant correlation of self-enhancement did not lead to a major problem here, because the main concern in the model relies on the positive view factor formed by the three positive views, not each individual view. Hence, the limitation of the self-enhancement measure used here did not undermine the purpose to investigate the pathways for positive views to maintain life satisfaction.

Another non-significant correlation was the correlation between have-want discrepancy and shifting tendency. This result is consistent with the finding in Wu's (in press a) study, suggesting that have-want discrepancy and shifting tendency are two independent constructs again. Moreover, the present study used 15 domains that were different from the 12 life domains used in $\mathrm{Wu}$ (in press a) study in assessing have-want discrepancy and shifting tendency for each participant. Despite this, the present study obtained similar results to $\mathrm{Wu}$ (in press a) study, such that (1) have-want discrepancy and shifting tendency have a nonsignificant correlation, (2) both have-want discrepancy and shifting tendency have positive relations with life satisfaction, and (3) have-want discrepancy and shifting tendency have unique effects on life satisfaction (from the structural equation model). These results reveal that the relationships between have-want discrepancy, shifting tendency and life satisfaction are replicable and show again that the two pathways in maintaining life satisfaction (reducing have-want discrepancy and changing importance perception) are independent.

In summary, this study extends Cummins and Nistico's (2002) notions on the positive cognitive bias of the three positive views and empirically examines the mediation pathways between positive views and life satisfaction, resolving the process of how positive views maintain life satisfaction. The major contribution of this study is to link the positive views regarding the self to mechanisms for life satisfaction by adding the effect of havewant discrepancy and shifting tendency to the model, thereby extending Cummins and Nistico's (2002) notions more directly to life satisfaction. Although there are several 
limitations in the present study, such as the measurement of self-enhancement and homogeneity of the sample (consisting of university students), this study still helps to resolve how positive views maintain life satisfaction.

Acknowledgement This research was partially supported by a grant form the Central Taiwan University of Science and Technology (CTU97-P-24) to Ying-Mei Tsai.

\section{References}

Brown, J. D., Collins, R. L., \& Schmidt, G. W. (1988). Self-esteem and direct versus indirect forms of selfenhancement. Journal of Personality and Social Psychology, 55, 445-453.

Calman, K. C. (1984). Quality of life of cancer patients-a hypothesis. Journal of Medical Ethics, 10, $124-127$.

Campbell, A., Converse, P. E., \& Rogers, W. L. (1976). The quality of American life: Perceptions, evaluations, and satisfaction. New York: Russell Sage Foundation.

Chamberlain, K., \& Zika, S. (1992). Stability and change in subjective well-being over short time periods. Social Indicators Research, 26, 101-117.

Cohen, E. H. (2000). A facet theory approach to examining overall and life facet satisfaction relationships. Social Indicators Research, 51, 223-237.

Crocker, J., Brook, A. T., Niiya, Y., \& Villacorta, M. (2006). The pursuit of self-esteem: Contingencies of self-worth and self-regulation. Journal of Personality, 74, 1749-1772.

Crocker, J., Karpinski, A., Quinn, D. M., \& Chase, S. (2003). When grades determine self-worth: Consequences of contingent self-worth for male and female engineering and psychology majors. Journal of Personality and Social Psychology, 85, 507-516.

Cummins, R. A. (1995). On the trail of the gold standard for subjective well-being. Social Indicators Research, 35, 179-200.

Cummins, R. A. (1998). The Second Approximation to an International Standard for Life Satisfaction. Social Indicators Research, 43, 307-334.

Cummins, R. A., \& Nistico, H. (2002). Maintaining life satisfaction: The role of positive cognitive bias. Journal of Happiness Studies, 3, 37-69.

Cummins, R. A., Gullone, E., \& Lau, A. L. D. (2002). A model of subjective well-being homeostasis: The role of personality. In A. Michalos (Ed.), Social indicators research series (Vol. 16, pp. 7-46). Dordrecht: Kluwer Academic Publishers.

Diener, E., \& Diener, M. (1995). Cross-cultural correlates of life satisfaction and self-esteem. Journal of Personality and Social Psychology, 68, 653-663.

Diener, E., Emmons, R. A., Larsen, R. J., \& Griffin, S. (1985). The satisfaction with life scale. Journal of Personality Assessment, 49, 71-75.

Hardy, L., \& Moriarty, T. (2006). Shaping self-concept: The elusive importance effect. Journal of Personality, 74, 377-402.

Hu, L., \& Bentler, P. M. (1999). Cutoff criteria for fit indices in covariance structure analysis: conventional versus new alternatives. Structural Equation Modeling, 6, 1-55.

Jansen, S. J., Stiggelbout, A. M., Nooij, M. A., Noordijk, E. M., \& Kievit, J. (2000). Response shift in quality of life measurement in early-stage breast cancer patients undergoing radiotherapy. Quality of Life Research, 9, 603-615.

Judge, T. A., Erez, A., Bono, J. E., \& Thoresen, C. J. (2002). Are measures of self-esteem, neuroticism, locus of control, and generalized self-efficacy? Journal of Personality and Social Psychology, 83, $693-710$.

Kobayashi, C., \& Brown, J. D. (2003). Self-esteem and self-enhancement in Japan and America. Journal of Cross-Cultural Psychology, 34, 567-580.

Koivumaa-Honkanen, H., Kaprio, J., Honkanen, R. J., Viinamäki, H., \& Koskenvuo, M. (2005). The stability of life satisfaction in a 15-year follow-up of adult Finns healthy at baseline. BMC Psychiatry, 5, 4.

Kurman, J. (2001). Self-enhancement: Is it restricted to individualistic cultures? Personality and Social Psychology Bulletin, 27, 1705-1716.

Lai, J. C. L., Cheung, H., Lee, W. E., \& Yu, H. (1998). The utility of the revised life orientation test to measure optimism among Hong Kong Chinese. International Journal of Psychology, 33, 45-56.

Lai, C. L., \& Yue, X. D. (2000). Measuring optimism in Hong Kong and mainland Chiense with the revised life orientation test. Personality and Individual Differences, 28, 781-796. 
Lefcourt, H. M. (1991). Locus of control. In J. P. Robinson, P. R. Shaver, \& L. S. Wrightsman (Eds.), Measures of personality and social psychological attitudes. San Diego: Academic Press.

Locke, E. A. (1969). What is job satisfaction? Organizational Behavior and Human Performance, 4 , 309-336.

Locke, E. A. (1976). The nature and causes of job satisfaction. In M. D. Dunnette (Ed.), Handbook of industrial and organizational psychology (pp. 1297-1343). Chicago: Rand McNally.

Makikangas, A., Kinnunen, U., \& Feldt, T. (2004). Self-esteem, dispositional optimism, and. health: Evidence from cross-lagged data on employees. Journal of Research in Personality, 38, 556-575.

Michalos, A. C. (1985). Multiple discrepancies theory (MDT). Social Indicators Research, 16, $347-413$.

Moskowitz, J. T., Folkman, S., Collette, L., \& Vittinghoff, E. (1996). Coping and mood during AIDS-related caregiving and bereavement. Annals of Behavioral Medicine, 18, 49-57.

Muthén, L. K., \& Muthén, B. O. (2007). Mplus user's guide (4th ed.). Los Angeles, CA: Muthén \& Muthén.

Paulhus, D. L., \& Van Selst, M. (1990). The Spheres of Control scale: Ten years of research. Personality and Individual Differences, 11, 1029-1036.

Pavot, W., \& Diener, E. (1993). Review of the satisfaction with life scale. Psychological Assessment, 5, $164-172$.

Pelham, B. W., \& Swann, W. B. (1989). From self-conceptions to self-worth: On the sources and structure of global self-esteem. Journal of Personality and Social Psychology, 57, 672-680.

Rapkin, B. D. (2000). Personal goals and response shifts: Understanding the impact of illness and events on the quality of life of people living with AIDS. In C. E. Schwartz \& M. A. G. Sprangers (Eds.), Adaptation to changing health: Response shift in quality of life research. Washington, DC: American Psychological Association.

Rapkin, B. D., \& Shwartz, C. E. (2004). Toward a theoretical model of quality of life appraisal: Implications of findings from studies of response shift. Health and Quality of Life Outcomes, 2, 14.

Robinson, J. P., Shaver, P. R., \& Wrightsman, L. S. (1991). Measures of personality and social psychological attitudes. San Diego, CA: Academic Press.

Rothbaum, F., Snyder, S. S., \& Weisz, J. R. (1982). The world and changing the self: A two-process model of perceived control. Journal of Personality and Social Psychology, 42, 5-37.

Scheier, M. F., Carver, C. S., \& Bridges, M. W. (1994). Distinguishing optimism from neuroticism (and trait anxiety, self-mastery and self-esteem): A reevaluation of the life orientation test. Journal of Personality \& Social Psychology, 67, 1063-1078.

Schulz, W. (1995). Multiple-discrepancies theory versus resource theory. Social Indicators Research, 34, $153-169$.

Schwartz, C. E., Coulthard-Morris, L., Cole, B., \& Vollmer, T. (1997). The quality-of-life effects of Interferon-Beta-1b in multiple sclerosis: An Extended Q-TWiST analysis. Archives of Neurology, 54, 1475-1480.

Shin, D. C., \& Johnson, D. M. (1978). Avowed happiness as an overall assessment of the quality of life. Social Indicators Research, 5, 475-492.

Spittal, M. J., Siegert, R. J., McClure, J. L., \& Walkey, F. H. (2001). The Spheres of Control Scale: The identification of a clear, replicable three-factor structure. Personality and Individual Differences, 32, $121-131$.

Swann, W. B., \& Ely, R. J. (1984). A battle of wills: Self-verification versus behavioral confirmation. Journal of Personality and Social Psychology, 47, 1287-1302.

Swann, W. B., Pelham, B. W., \& Chidester, T. R. (1988). Change through paradox: Using self-verification to alter beliefs. Journal of Personality and Social Psychology, 54, 268-273.

Swann, W. B., \& Read, S. J. (1981). Self-verification processes: How we sustain our self-conceptions. Journal of Experimental Social Psychology, 17, 351-372.

Swann, W. B., Rentfrow, P. J., \& Guinn, J. (2002). Self-verification: The search for coherence. In M. Leary \& J. Tagney (Eds.), Handbook of self and identity. New York: Guilford.

Tunali, B., \& Power, T. G. (1993). Creating satisfaction: A psychological perspective on stress and coping in families of handicapped children. Journal of child psychology and psychiatry, 34, 945-957.

Vermunt, R., Spaans, E., \& Zorge, F. (1989). Satisfaction, happiness and well-being of Dutch students. Social Indicators Research, 21, 1-33.

Welham, J., Haire, M., Mercer, D., \& Stedman, T. (2001). A gap approach to exploring quality of life in mental health. Quality of Life Research, 10, 421-429.

Wood, J. V., Giordano-Beech, M., Taylor, K. L., Michela, J. L., \& Gaus, V. (1994). Strategies of social comparison among people with low self-esteem. Journal of Personality and Social Psychology, 64, $779-793$. 
Wrosch, C., \& Heckhausen, J. (1999). Control processes before and after passing a developmental deadline: Activation and deactivation of intimate relationship goals. Journal of Personality and Social Psychology, 77, 415-427.

Wrosch, C., Scheier, M. F., Miller, G. E., Schulz, R., \& Carver, C. S. (2003). Adaptive self-regulation of unattainable goals: Goal disengagement, goal re-engagement, and subjective well-being. Personality and Social Psychology Bulletin, 29, 1494-1508.

$\mathrm{Wu}, \mathrm{C}$. H. (In press a). Enhancing quality of life by shifting importance perception among life domains. Journal of Happiness Studies.

$\mathrm{Wu}, \mathrm{C}$. H. (In press b). The role of perceived discrepancy in satisfaction evaluation. Social Indicators Research.

Wu, C. H., \& Yao, G. (2006a). Do we need to weight item satisfaction by item importance? A perspective from Locke's range-of-affect hypothesis. Social Indicators Research, 79, 485-502.

Wu, C. H., \& Yao, G. (2006b). Do we need to weight satisfaction scores with importance ratings in measuring quality of life? Social Indicators Research, 78, 305-326.

Wu, C. H., \& Yao, G. (2006c). Analysis of factorial invariance across gender in the Taiwan version of the satisfaction with Life Scale. Personality and Individual Differences, 40, 1259-1268.

Wu, C. H., \& Yao, G. (2007). Relations among self-certainty, sense of control and quality of life. International Journal of Psychology, 42, 342-352. 